\title{
Functionalized Nanocellulose-Integrated Heterolayered
}

\section{Nanomats toward Smart Battery Separators}

\author{
Jung-Hwan Kim, ${ }^{\dagger 1}$ Minsu Gu, ${ }^{\dagger 1}$ Do Hyun Lee, ${ }^{1}$ Jeong-Hoon Kim, ${ }^{1}$ Yeon-Su Oh, ${ }^{1}$ Sa Hoon \\ Min, ${ }^{1} *$ Byeong-Su Kim ${ }^{1,2} *$ and Sang-Young Lee ${ }^{1} *$ \\ ${ }^{1}$ Department of Energy Engineering, School of Energy and Chemical Engineering and \\ ${ }^{2}$ Department of Chemistry, School of Natural Science, Ulsan National Institute of Science \\ and Technology (UNIST), Ulsan 44919, Republic of Korea
}

$\dagger$ These authors contributed equally to this work.

E-mail: minshu21@unist.ac.kr (S. H. Min); bskim19@unist.ac.kr (B.-S. Kim); syleek@unist.ac.kr (S.-Y. Lee) 


\section{Methods:}

Synthesis of terpyridine (TPY) ligand. Terpyridine was synthesized and modified using the protocol reported previously in the literature. ${ }^{1}$ Potassium hydroxide $(\mathrm{KOH})$ pellets $(1.15 \mathrm{~g})$ and $23 \mathrm{~mL}$ of ammonia (28\%) were added to a mixture of 2-acetylpyridine (1.685 $\mathrm{mL})$ and 4cyanobenzaldehyde $(0.98 \mathrm{~g})$ in anhydrous ethanol $(50 \mathrm{~mL})$, and the resulting mixture was stirred for $24 \mathrm{~h}$ at $34{ }^{\circ} \mathrm{C}$. The mixture was subsequently cooled in an ice bath and processed using vacuum filtration with a washing step using ice-cold anhydrous ethanol. The filtered powder was recrystallized with anhydrous ethanol, resulting in a pure white powder. One gram of the obtained white powder dissolved in $35 \mathrm{~mL}$ of THF was slowly added via a syringe pump to a solution of lithium aluminium hydride $(0.50 \mathrm{~g})$ dissolved in $35 \mathrm{~mL}$ of THF. The mixture was stirred for $12 \mathrm{~h}$ at $25^{\circ} \mathrm{C}$ under a nitrogen atmosphere. After the reaction, an additional $50 \mathrm{~mL}$ of THF was added and the mixture was subsequently processed using vacuum filtration with vigorous washing with THF. The filtered yellowish solution was evaporated using a rotary evaporator. The resulting powder was dissolved in dichloromethane (DCM), and $\mathrm{HCl}$ gas was then pumped into the solution for $90 \mathrm{~min}$. The formed precipitate was filtered and dissolved in deionized (DI) water. To further purify the synthesized TPY, a 0.10 $\mathrm{M} \mathrm{NaOH}$ solution was added to the aqueous solution and extracted with DCM. The extract was evaporated and then dissolved in $0.10 \mathrm{M} \mathrm{HCl}$ solution to a concentration of 30 $\mathrm{mg} \mathrm{mL}{ }^{-1}$.

Synthesis of functionalized nanocellulose with TPY (TPY-CNF). The nanocellulose suspension was produced by repeated high-pressure homogenization of pretreated wood cellulose powders (particle size $\sim 45 \mu \mathrm{m}, \mathrm{KC}$ Flock, Nippon Paper Chemicals) in water. The detailed procedure for preparing the CNF suspension is described in our previous publications. ${ }^{2}$ To oxidize the nanocellulose, a $0.50 \mathrm{wt} \%$ cellulose suspension $(100 \mathrm{~mL})$ was 
mixed with 2,2,6,6-tetramethylpiperidine-1-oxyl (TEMPO, $14.75 \mathrm{mg}$ ), sodium bromide $(\mathrm{NaBr}, 162 \mathrm{mg})$ and $5 \mathrm{wt} \%$ sodium hypochlorite solution $(\mathrm{NaClO}, 10 \mathrm{~mL})$ for $6 \mathrm{~h}$. The resulting mixture was washed with DI water by centrifugation. This oxidized nanocellulose suspension $(50 \mathrm{~mL})$ was then reacted with the as-synthesized TPY solution $(4.0 \mathrm{~mL})$ for $12 \mathrm{~h}$ in the presence of $N$-ethyl- $N$ '-(3-dimethylaminopropyl)carbodiimide methiodide (EDC, 238 mg). The resulting suspension was washed with DI water by centrifugation.

DFT calculations. To compare the binding energy of $\mathrm{Mn}^{2+}$ complexes, we performed DFT calculations using the Gaussian 09 program. ${ }^{3} \mathrm{Mn}^{2+}\left(\mathrm{PP}_{3}\right), \mathrm{Mn}^{2+}(\mathrm{Glc})$, and $\mathrm{Mn}^{2+}(\mathrm{TPY})$ were introduced as model complexes for the PP, CNF, and TPY, respectively. The spin multiplicity for the ground state of $\mathrm{Mn}^{2+}$ complexes was set to sextet. Geometry optimizations were calculated at the level of B3LYP/6-31G(d,p), and accurate single-point energies were obtained at the level of B3LYP/6-311+G(2d,2p) from the optimized geometries. The basis set superposition error (BSSE) corrections were also considered in the binding energy calculations.

MD simulations. To test the binding stability of $\mathrm{Mn}^{2+}$ ions, we performed all-atom MD simulations using the AMBER force field. ${ }^{4,5}$ Microcrystalline models (approximately $6 \mathrm{~nm}$ in both length and width) of syndiotactic PP, cellulose I $\beta$, and cellulose I $\beta$ with 4 TPY groups were placed in parallel with the $x y$-plane of the simulation box. In the case of cellulose, the (010) exposed surface was built using the Cellulose-Builder toolkit. ${ }^{6} \mathrm{The}_{\mathrm{Mn}^{2+}}$ ions were set to be positioned at each model surface, and the simulation box was then filled with 1,600 EC molecules and $8 \mathrm{PF}_{6}^{-}$ions. The generalized AMBER forcefield (GAFF) parameters ${ }^{4}$ were used for the PP, EC, and TPY group, and the cellulose was parameterized by the GLYCAM06 forcefield. ${ }^{5}$ The $\mathrm{PF}_{6}{ }^{-}$ion model was taken from the literature. ${ }^{7}$ All partial charges on the PP, EC, and TPY group were calculated using the AM1-BCC method in 
AmberTools $14{ }^{8}$ The MD simulations and visualizations were performed using the Amber14 and VMD software packages, ${ }^{9}$ respectively. After the energy of the initial conformation was minimized, each system was relaxed by a 100-ps canonical (NVT) and 500-ps isothermalisobaric (NPT) MD simulation at $333 \mathrm{~K}$. For the production run, long NPT MD simulations were calculated at $333 \mathrm{~K}$ and $P=1$ bar using the Langevin thermostat with a collision frequency of $1.0 \mathrm{ps}^{-1}$ and the Berendsen barostat with a coupling constant of $2.0 \mathrm{ps}$. The cutoff distance of $1.0 \mathrm{~nm}$ and the particle mesh Ewald (PME) method were applied to the short-range nonbonding interactions and the long-range electrostatic interactions, respectively. All bond lengths involving $\mathrm{H}$ atoms were constrained with the SHAKE algorithm, ${ }^{10}$ and a time step of 2 fs was used.

Structural design and fabrication of the c-mat separator. To fabricate the electrospun macroporous mat, we used electrospinning with PVP/PAN blends. The blended PAN $\left(\right.$ molecular weight $\left.=150,000 \mathrm{~g} \mathrm{~mol}^{-1}\right)$ and PVP $\left(\right.$ molecular weight $\left.=1,300,000 \mathrm{~g} \mathrm{~mol}^{-1}\right)$ solution was prepared by dissolving the polymers in dimethylacetamide (DMAc) at $70{ }^{\circ} \mathrm{C}$ for $12 \mathrm{~h}$, where the total polymer concentration was $20 \mathrm{wt} . \%$ and the relative composition ratio of PVP/PAN was 50/50 (w/w). The electrospinning conditions were $8.0 \mathrm{kV}$ and a feed rate of 3.5 $\mu \mathrm{L} \mathrm{min}{ }^{-1}$. The resulting electrospun PVP/PAN mat was collected on a stainless steel plate positioned $10 \mathrm{~cm}$ from the nozzles. After being roll-pressed at room temperature, a freestanding macroporous electrospun mat (thickness $\sim 19 \mu \mathrm{m}$ ) was produced. The c-mat separators were fabricated via a simple vacuum-assisted infiltration process. The TPY-CNF suspension was poured onto a PVP/PAN mat positioned inside a porcelain Büchner funnel and then subjected to a vacuum to infiltrate the porous mat, leading to the formation of a hierarchical/asymmetric porous structure. The thickness of the TPY-CNF layer was 
controlled by varying the amount of the TPY-CNF suspension. The final c-mat separator (thickness $\sim 20 \mu \mathrm{m}$ ) was obtained with a 1- $\mu$ m-thick TPY-CNF layer. A commercial PP/PE/PP separator (thickness $\sim 20 \mu \mathrm{m}$, Celgard) was chosen as the control sample.

Characterizations of TPY-CNF. The ${ }^{1} \mathrm{H}$ NMR spectra of TPY were acquired using a VNMRS 600 spectrometer operated at $600 \mathrm{MHz}$; the samples were dissolved in DMSO solvent. A mass analysis of TPY was carried by mass spectroscopy (450-GC \& 320-MS, Bruker). Fourier transform infrared (FT-IR) spectra were collected using an FT-IR spectrophotometer (670-IR, Varian). X-ray photoelectron spectroscopy (XPS, Thermo Fisher, K-alpha) was used to detect the chemical state of TPY-CNF.

Structural/physicochemical characterizations of the c-mat separator. The surface and cross-sectional morphologies of the separators were characterized by field emission scanning electron microscopy (FE-SEM, Hitachi) in conjunction with energy-dispersive X-ray spectroscopy (EDS). The pore size distribution of the c-mat separator was measured using mercury intrusion porosimetry (AutoPore IV 9500, Micromeritics Instrument Corp.). The thermal shrinkage of the separators was evaluated by measuring their (area-based) dimensional change after exposure to $150{ }^{\circ} \mathrm{C}$ for $0.5 \mathrm{~h}$. For the electrochemical characterization of the separators, a liquid electrolyte of $1 \mathrm{M} \mathrm{LiPF}_{6}$ in EC/DEC (1/1 (v/v), Soulbrain) was employed. The electrolyte wettability of the separators was quantitatively estimated by measuring the separators' electrolyte immersion height.

Electrochemical properties of the c-mat separator and its application to lithium-ion batteries. The electrochemical stability window of the separators was measured by a linear sweep voltammetry experiment performed on a working electrode of stainless steel and a counter and reference electrode of lithium metal at a scan rate of $1.0 \mathrm{mV} \mathrm{s}^{-1}$. The open-circuit 
voltage (OCV) drop in the fully charged cell (at a current density of $0.2 \mathrm{C}$ ) was monitored as a function of elapsed time. The ionic conductivity of the separator was examined by AC impedance analysis (VSP classic, Bio-Logic) over the frequency range from $10^{-2}$ to $10^{6} \mathrm{~Hz}$. A pouch-type cell (width $\times$ length $=30 \times 40 \mathrm{~mm}^{2}$ ) was assembled by sandwiching a separator between the LMO cathode $(\mathrm{LMO} /$ carbon black/PVdF $=92 / 3 / 5 \mathrm{w} / \mathrm{w} / \mathrm{w}$, areal mass loading $=$ $17 \mathrm{mg} \mathrm{cm}^{-2}$ ) and the Li metal anode (the TPY-CNF top layer was in contact with the LMO cathode while the PVP/PAN support layer faced the Li metal anode), and the cell was activated by being filled with the liquid electrolyte $\left(1 \mathrm{M} \mathrm{LiPF}_{6}\right.$ in $\left.\mathrm{EC} / \mathrm{DEC}=1 / 1 \mathrm{v} / \mathrm{v}\right)$. The cell performance was investigated using a cycle tester (PNE Solution) at 25 and $60{ }^{\circ} \mathrm{C}$ under various charge/discharge conditions. 
Figure S1. (a) ${ }^{1} \mathrm{H}$ NMR spectra and (b) mass analysis of TPY.

Figure S2. SEM images of the PP/PE/PP separator.

Figure S3. Discharge profiles of cells assembled with (a) PP/PE/PP separator and c-mat separator with TPY-CNF layers with thicknesses of (b) $1 \mu \mathrm{m}$, (c) $3 \mu \mathrm{m}$ and (d) $10 \mu \mathrm{m}$.

Figure S4. A photograph showing the structural disruption of the electrospun mat after the mat was immersed in a liquid electrolyte $\left(1 \mathrm{M} \mathrm{LiPF}_{6}\right.$ in $\left.\mathrm{EC} / \mathrm{DEC}=1 / 1(\mathrm{v} / \mathrm{v})\right)$ : (a) PVP electrospun mat and (b) PVP/PAN electrospun mat.

Figure S5. Variation in the XPS spectra (characteristic peak of nitrogen atoms) of PVP/PAN or PAN films after the films were swelled in a liquid electrolyte $\left(1 \mathrm{M} \mathrm{LiPF}_{6}\right.$ in $\mathrm{EC} / \mathrm{DEC}=1 / 1$ v/v) containing dissolved HF (100 ppm): (a) PVP/PAN film and (b) PAN film.

Figure S6. Characterization of the separator properties. (a) Linear sweep voltammograms. (b) Electrolyte wettability. (c) Effect of polar electrolyte (here, $1 \mathrm{M} \mathrm{LiPF}_{6}$ in EC/PC = 1/1 (v/v)) on wettability of separators and charge/discharge performance of cells incorporating $\mathrm{PP} / \mathrm{PE} / \mathrm{PP}$ separator and c-mat separator. (d) Thermal shrinkage after exposure to $150{ }^{\circ} \mathrm{C} / 0.5 \mathrm{~h}$.

Figure S7. Comparison of the cell performance (at room temperature) of the c-mat and PP/PE/PP separators: (a) Discharge rate capability (LMO cathode/Li metal anode), (b) Discharge rate capability (LCO cathode/natural graphite anode), and (c) Cycling performance (LMO cathode/Li metal anode).

Figure S8. (a) Impedance spectra and (b) summary of the fitting results for the c-mat and $\mathrm{PP} / \mathrm{PE} / \mathrm{PP}$ separators after cycling (at $60^{\circ} \mathrm{C}$ ). The inset in part (a) represents the equivalent circuit. Units of $R_{b}, R_{s f}$ and $R_{c t}$ are in ohms. $R_{b}$ is the bulk resistance, $R_{s f}$ is the surface 
resistance, and $\mathrm{R}_{\mathrm{ct}}$ is the charge transfer resistance. $\mathrm{CPE}_{\mathrm{sf}}$ and $\mathrm{CPE}_{\mathrm{ct}}$ are the constant phase elements at high and low frequencies, respectively.

Figure S9. SEM images showing the long-term structural stability (after 100 charge/discharge cycles at $60{ }^{\circ} \mathrm{C}$ ) of the c-mat separator: (a) TPY-CNF top layer and (b) PVP/PAN support layer.

Figure S10. Comparison of high-temperature $\left(60^{\circ} \mathrm{C}\right)$ cycling performance between the cell (I) and cell (II), in which the TPY-CNF top layer was in contact with the LMO cathode (for cell (I)) and positioned toward the Li metal anode (for cell (II)).

Table S1. Basic separator properties of the c-mat and PP/PE/PP separators. 

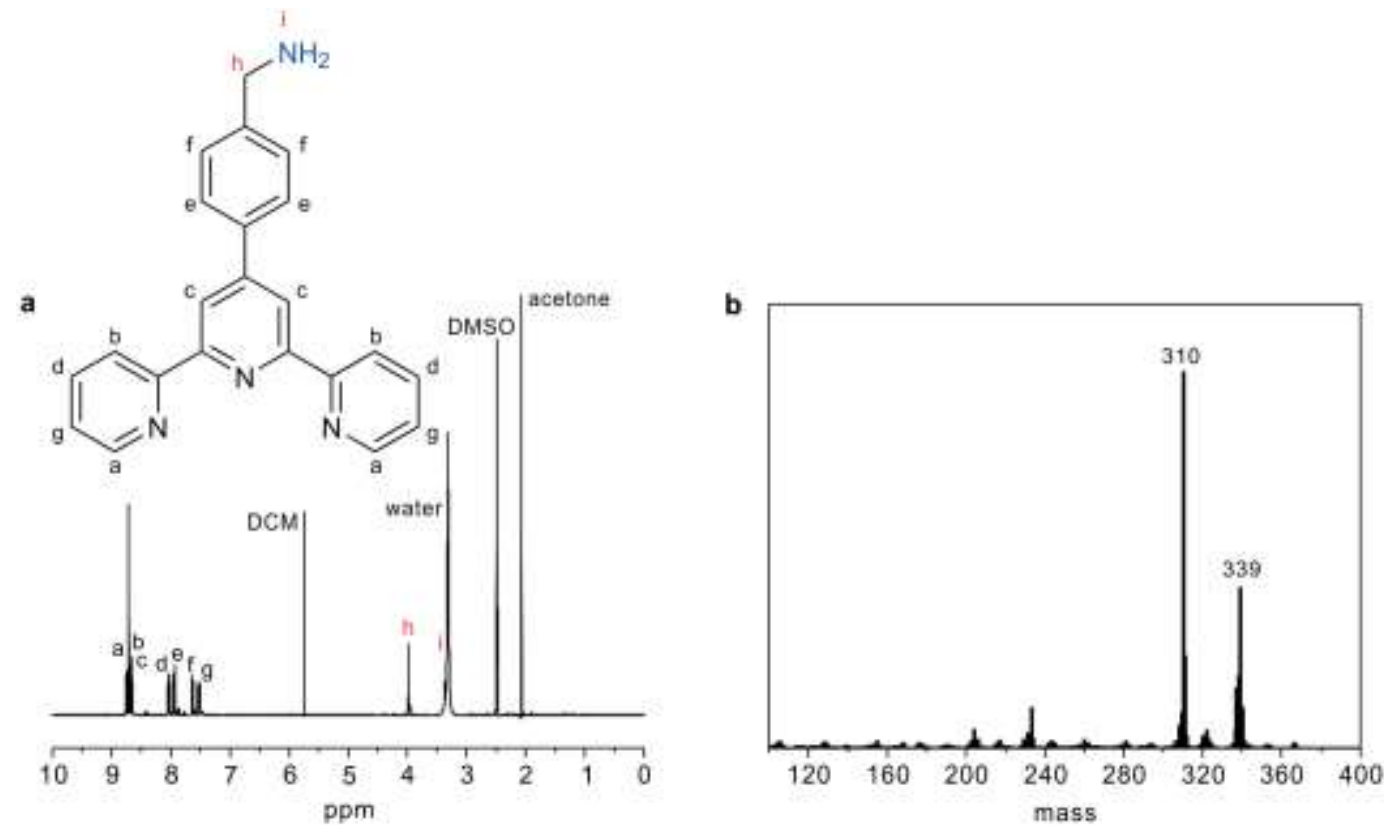

Figure S1. (a) ${ }^{1} \mathrm{H}$ NMR spectra and (b) mass analysis of TPY.
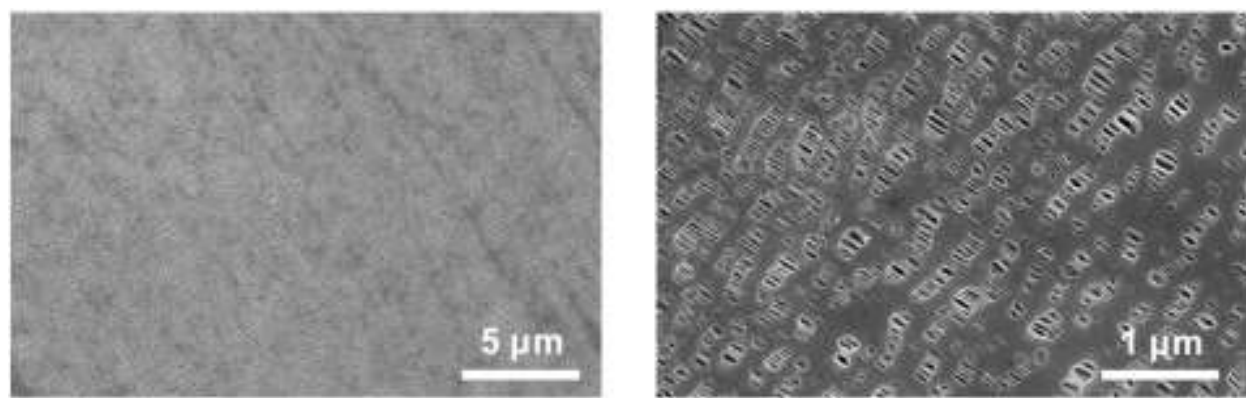

Figure S2. SEM images of the PP/PE/PP separator. 

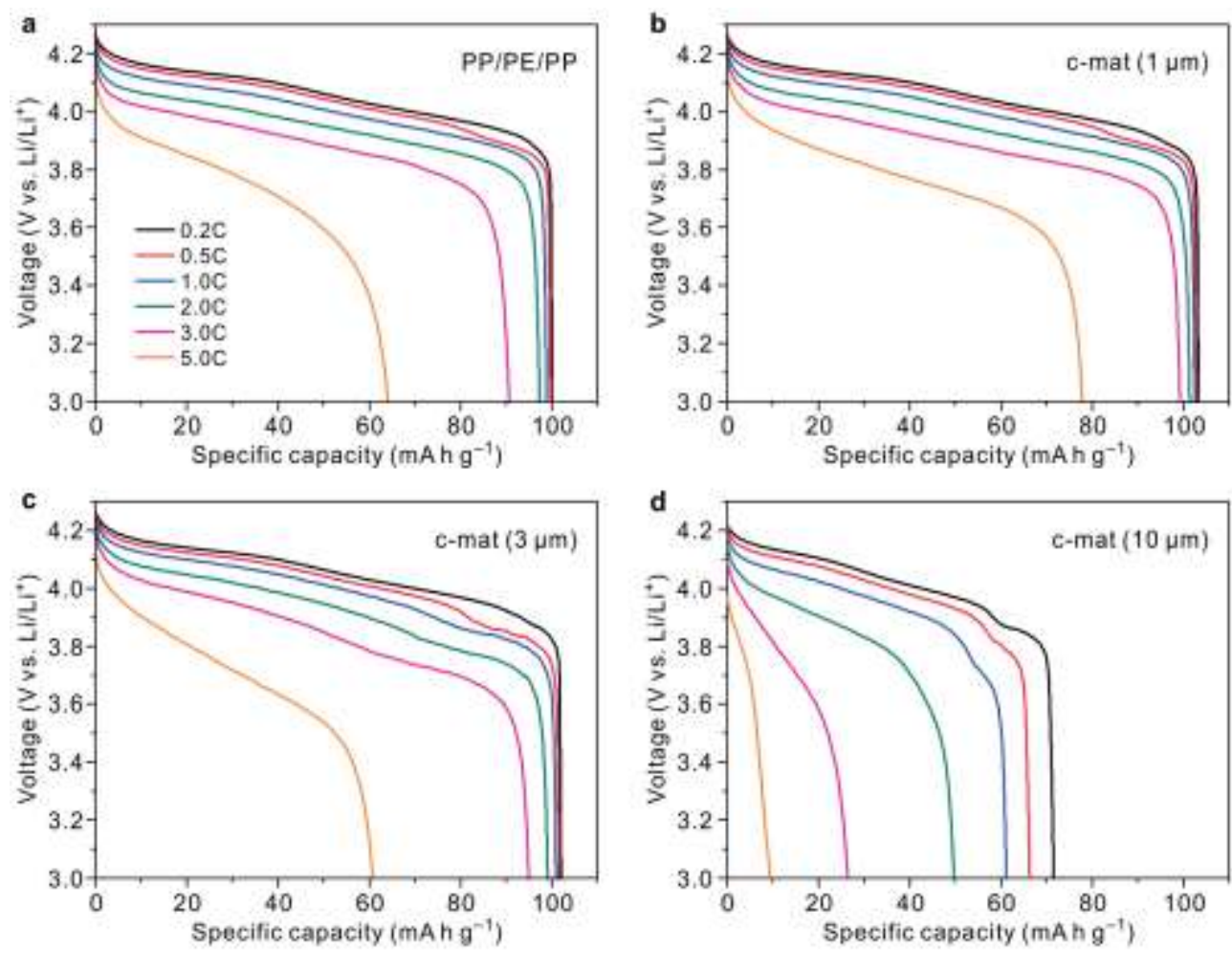

Figure S3. Discharge profiles of cells assembled with (a) PP/PE/PP separator and c-mat separator with TPY-CNF layers with thicknesses of (b) $1 \mu \mathrm{m}$, (c) $3 \mu \mathrm{m}$ and (d) $10 \mu \mathrm{m}$. 

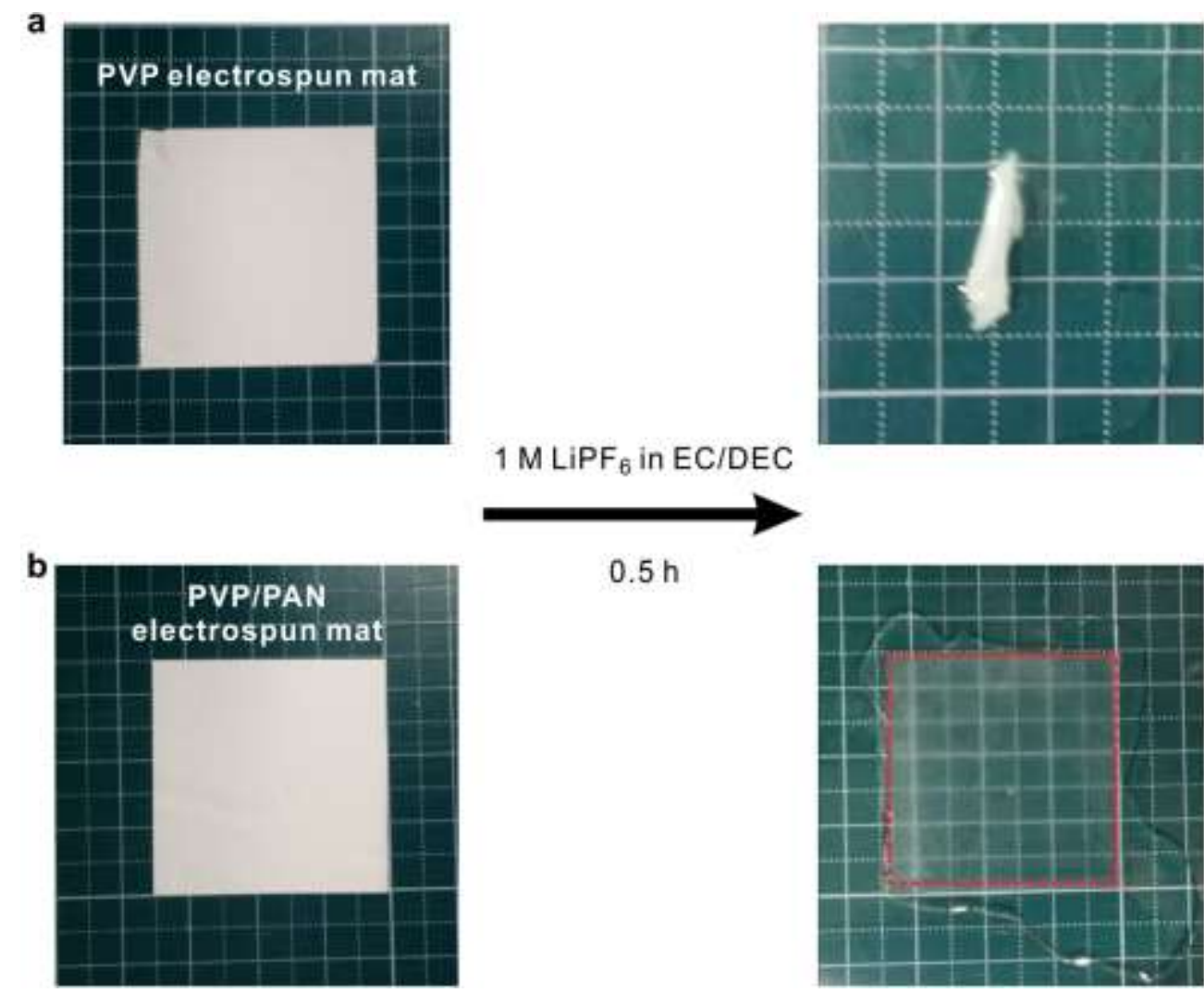

$0.5 \mathrm{~h}$

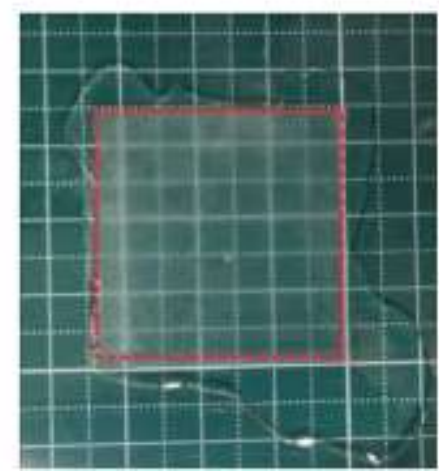

Figure S4. A photograph showing the structural disruption of the electrospun mat after the mat was immersed in a liquid electrolyte $\left(1.0 \mathrm{M} \mathrm{LiPF}_{6}\right.$ in $\left.\mathrm{EC} / \mathrm{DEC}=1 / 1(\mathrm{v} / \mathrm{v})\right)$ : (a) PVP electrospun mat and (b) PVP/PAN electrospun mat. 
a

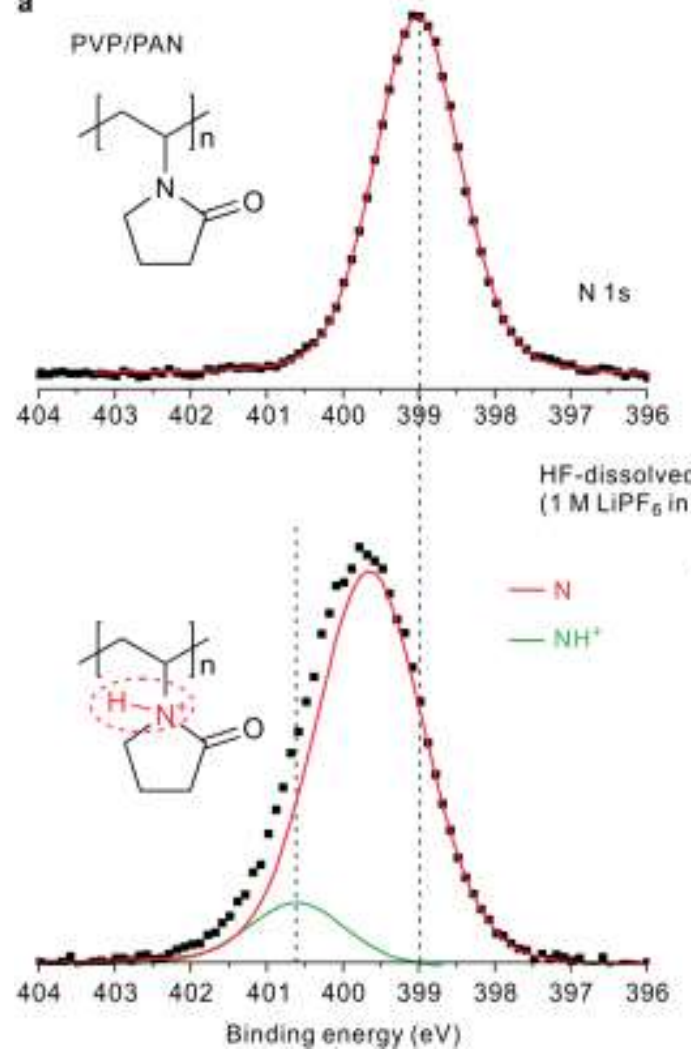

b

b PAN

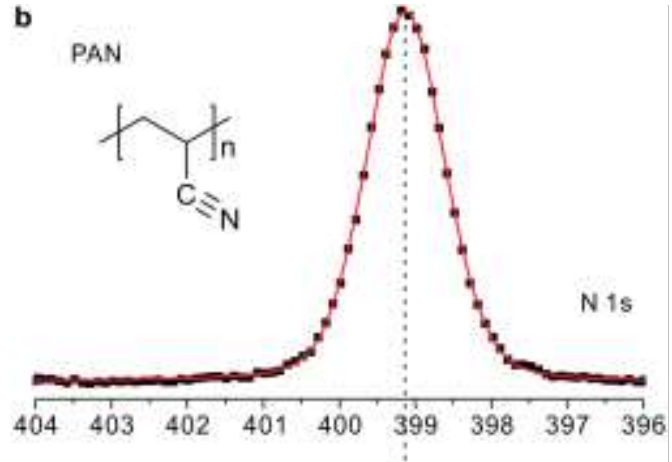

liquid electrolyte

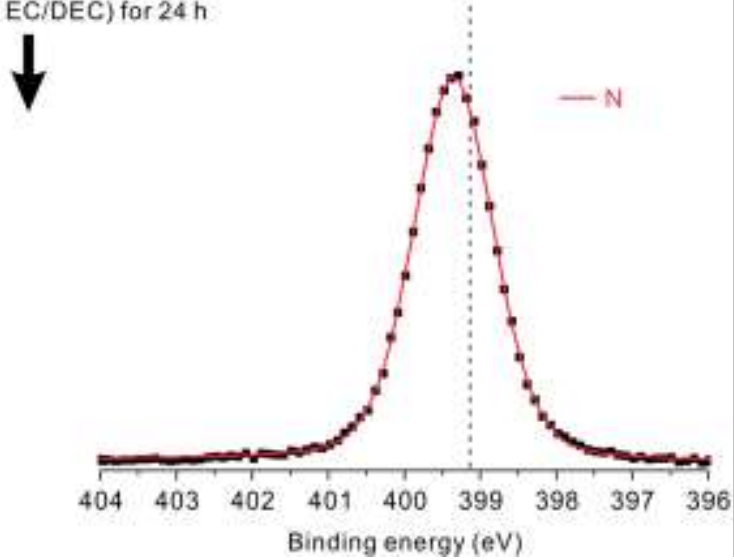

Figure S5. Variation in the XPS spectra (characteristic peak of nitrogen atoms) of PVP/PAN or PAN films after the films were swelled in a liquid electrolyte $\left(1.0 \mathrm{M} \mathrm{LiPF}_{6}\right.$ in $\mathrm{EC} / \mathrm{DEC}=$ 1/1 v/v) containing dissolved HF (100 ppm): (a) PVP/PAN film and (b) PAN film. 


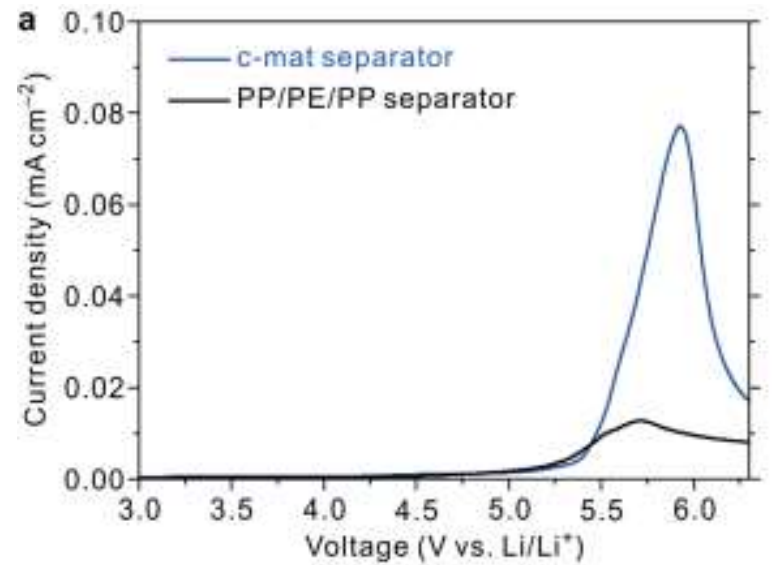

b
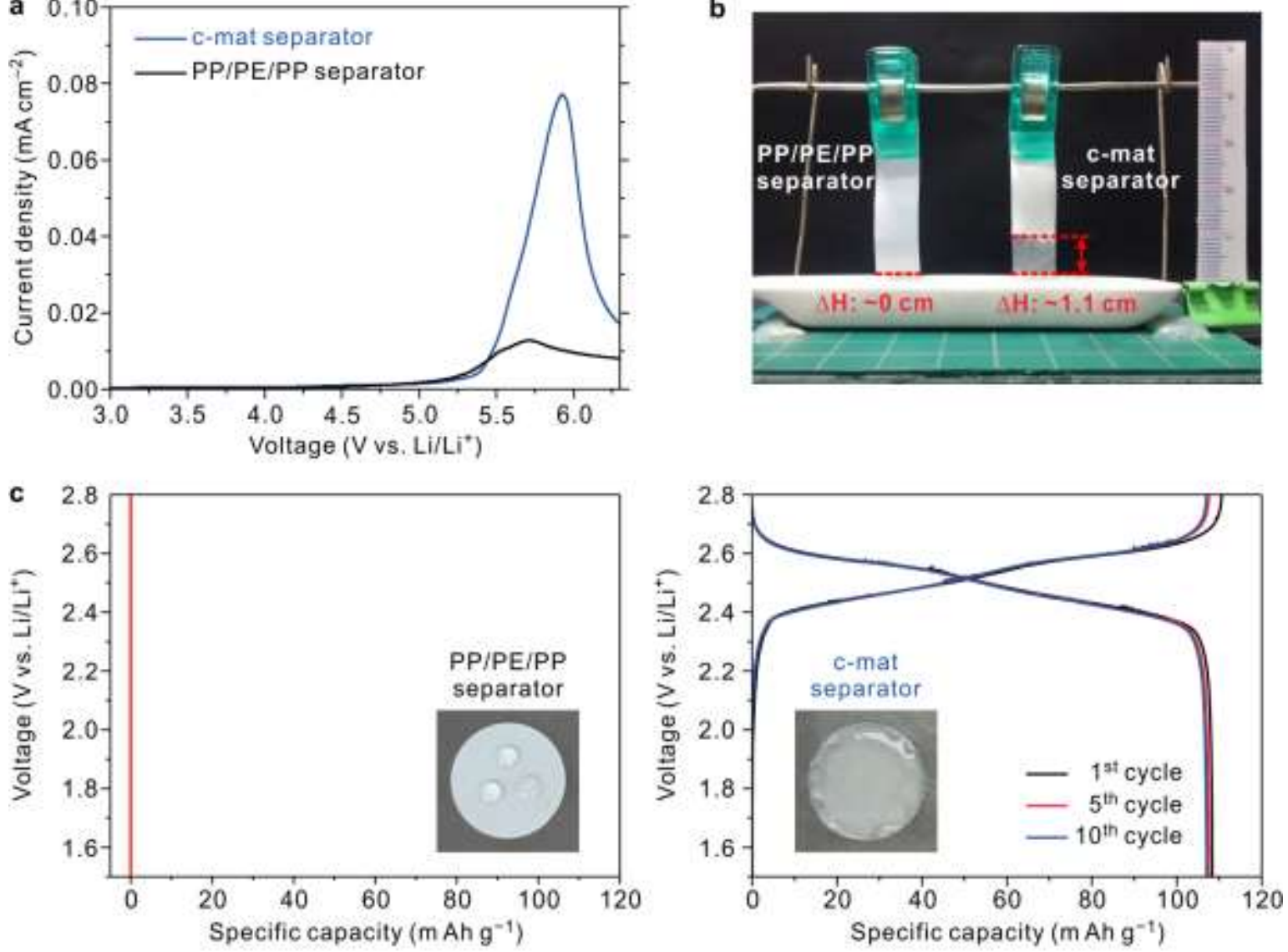

d
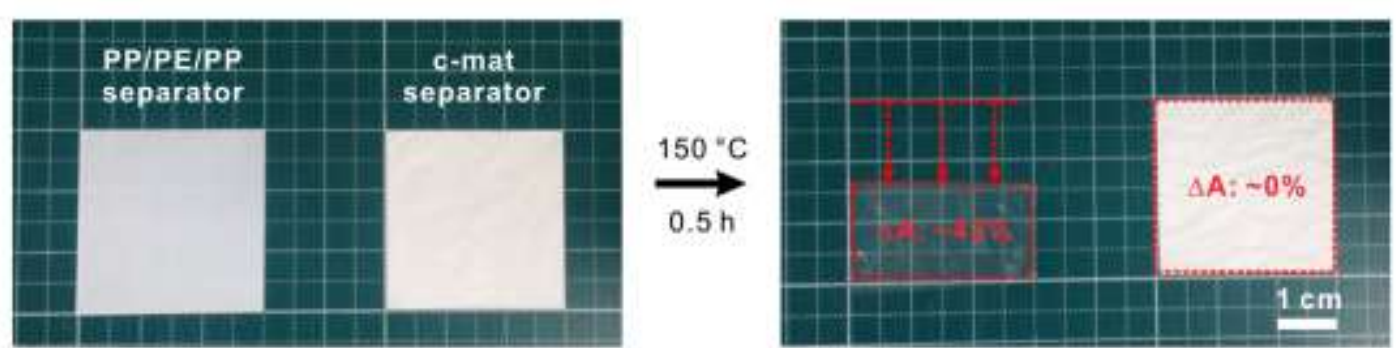

Figure S6. Characterization of the separator properties. (a) Linear sweep voltammograms. (b)

Electrolyte wettability. (c) Effect of polar electrolyte (here, 1.0 $\mathrm{M} \mathrm{LiPF}_{6}$ in $\mathrm{EC} / \mathrm{PC}=1 / 1$ (v/v)) on wettability of separators and charge/discharge profiles of cells incorporating $\mathrm{PP} / \mathrm{PE} / \mathrm{PP}$ separator and c-mat separator. (d) Thermal shrinkage after exposure to $150{ }^{\circ} \mathrm{C} / 0.5 \mathrm{~h}$. 

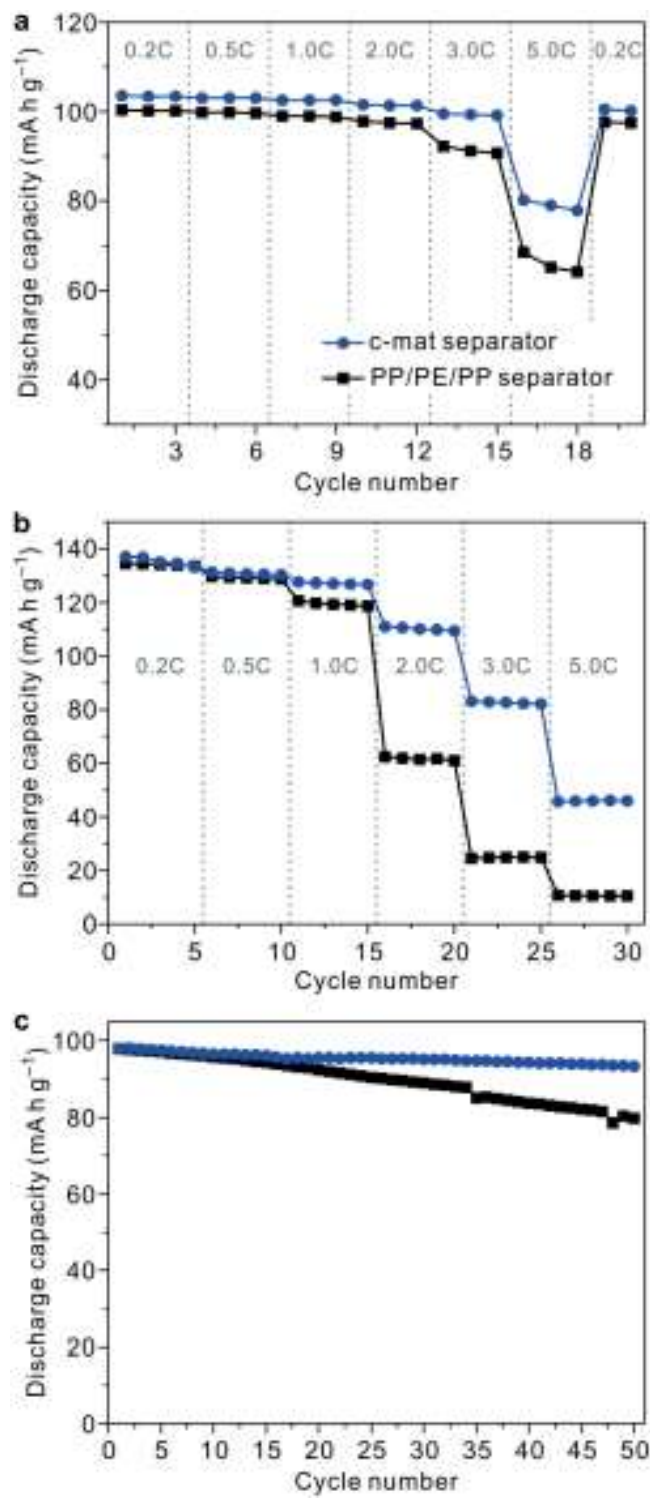

Figure S7. Comparison of the cell performance (at room temperature) of the c-mat and PP/PE/PP separators: (a) Discharge rate capability (LMO cathode/Li metal anode), (b) Discharge rate capability (LCO cathode/natural graphite anode), and (c) Cycling performance (LMO cathode/Li metal anode). 


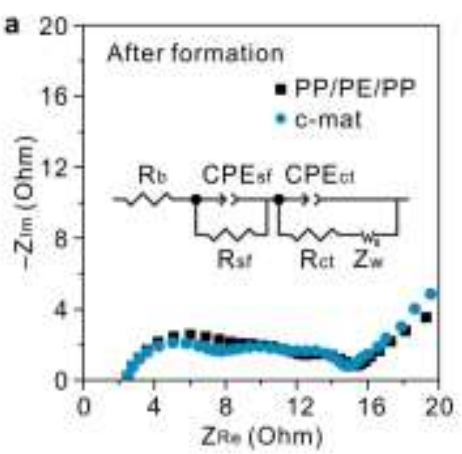

\begin{tabular}{cccccccc}
\hline \multirow{2}{*}{ Sample } & \multicolumn{3}{c}{ After $1^{\text {st }}$ cycle } & \multicolumn{3}{c}{ After $100^{\text {th }}$ cycle } \\
\cline { 2 - 7 } & $R_{t}$ & Rot & Rot & Ro & Rst & Rot \\
\hline c-mat & 1.9 & 4.1 & 11.1 & 4.9 & 12.9 & 27.1 \\
\hline PP/PE/PP & 2.4 & 4.3 & 11.7 & 9.0 & 58.3 & 222.8 \\
\hline
\end{tabular}

Figure S8. (a) Impedance spectra and (b) summary of the fitting results for the c-mat and $\mathrm{PP} / \mathrm{PE} / \mathrm{PP}$ separators after cycling $\left(\right.$ at $60^{\circ} \mathrm{C}$ ). The inset in part (a) represents the equivalent circuit. Units of $R_{b}, R_{s f}$ and $R_{c t}$ are in ohms. $R_{b}$ is the bulk resistance, $R_{s f}$ is the surface resistance, and $\mathrm{R}_{\mathrm{ct}}$ is the charge transfer resistance. $\mathrm{CPE}_{\mathrm{sf}}$ and $\mathrm{CPE}_{\mathrm{ct}}$ are the constant phase elements at high and low frequencies, respectively. 

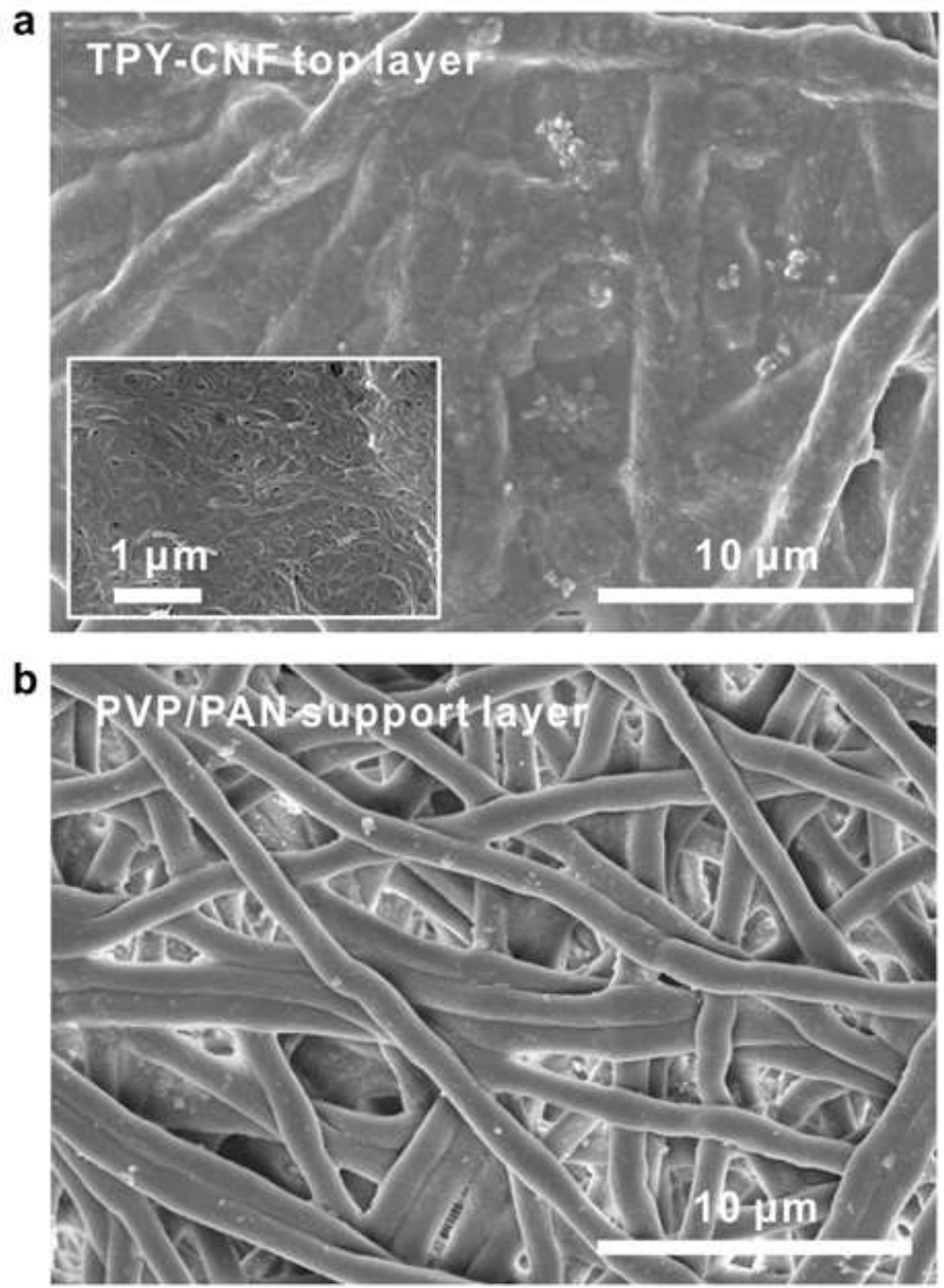

Figure S9. SEM images showing the long-term structural stability (after 100 charge/discharge cycles at $60{ }^{\circ} \mathrm{C}$ ) of the c-mat separator: (a) TPY-CNF top layer and (b) PVP/PAN support layer. 


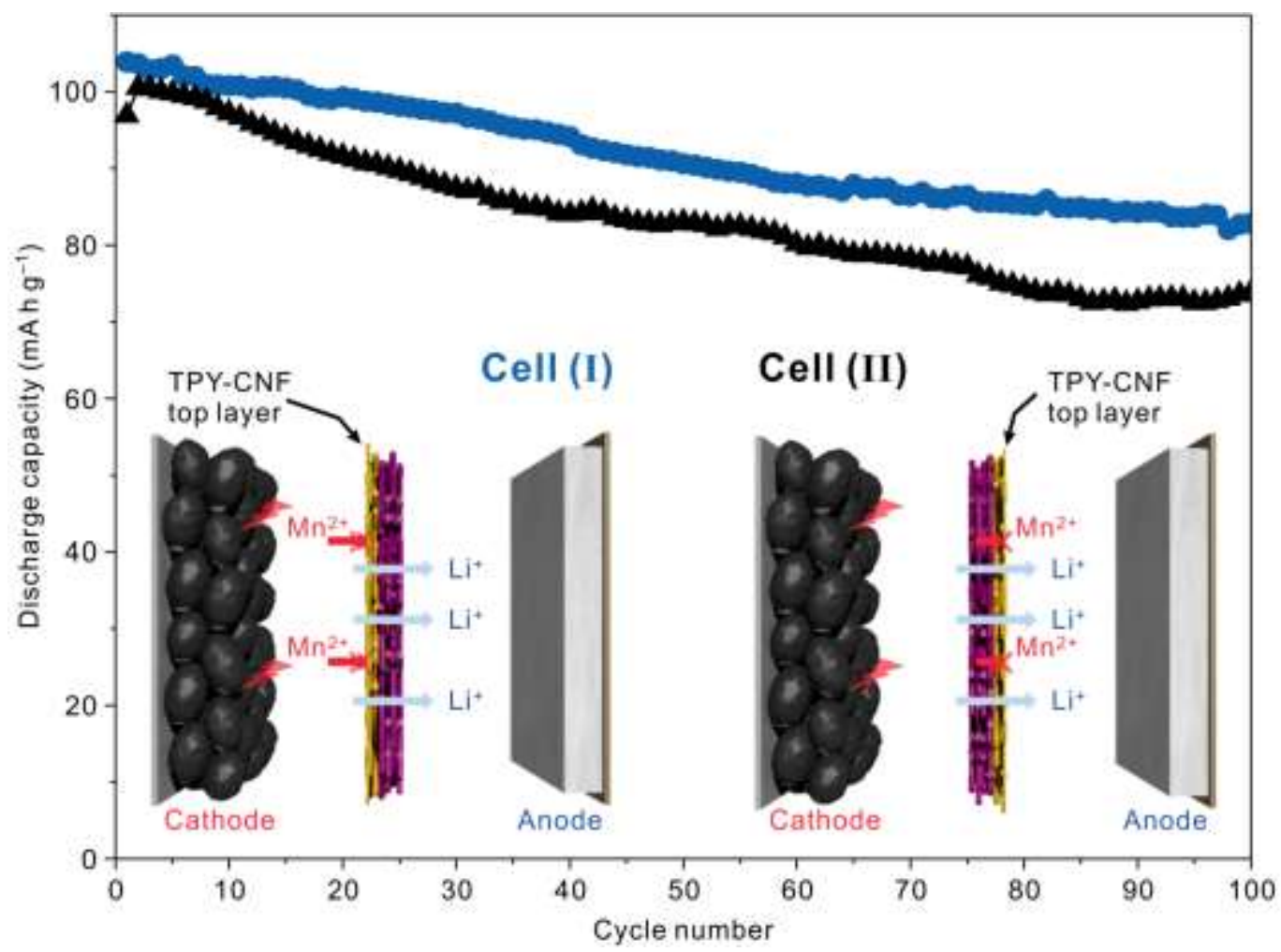

Figure S10. Comparison of high-temperature $\left(60^{\circ} \mathrm{C}\right)$ cycling performance between the cell (I) and cell (II), in which the TPY-CNF top layer was in contact with the LMO cathode (for cell (I)) and positioned toward the Li metal anode (for cell (II)). 
Table S1. Basic separator properties of the c-mat and PP/PE/PP separators.

\begin{tabular}{ccccc}
\hline & Thickness & Gurley value & Porosity & $\begin{array}{c}\text { Ionic } \\
\text { conductivity }\end{array}$ \\
\cline { 2 - 5 } & $\mu \mathrm{m}$ & $\mathrm{s} 100 \mathrm{cc} \mathrm{air}^{-1}$ & $\%$ & $\mathrm{mS} \mathrm{cm}^{-1}$ \\
\hline c-mat separator & $\sim 20$ & 10 & $\sim 65$ & 0.75 \\
\hline $\begin{array}{c}\text { PP/PE/PP } \\
\text { separator }\end{array}$ & $\sim 20$ & 500 & $\sim 40$ & 0.6 \\
\hline
\end{tabular}




\section{REFERENCES}

1. Kong, B.; Zhu, A.; Ding, C.; Zhao, X.; Li, B.; Tian, Y. Adv. Mater. 2012, 24, 5844-5848.

2. Chun, S.-J.; Choi, E.-S.; Lee, E.-H.; Kim, J. H.; Lee, S.-Y.; Lee, S.-Y. J. Mater. Chem. 2012, 22, 16618-16626.

3. Frisch, M. J.; Trucks, G. W.; Schlegel, H. B.; Cheeseman, J. R.; Scalmani, G.; Barone, V.; Mennucci, B.; Petersson, G. A. Gaussian 09, revision C. 01.; Gaussian Inc., 2010.

4. Wang, J.; Wolf, R. M.; Caldwell, J. W.; Kollman, P. A.; Case, D. A. J. Comput. Chem. 2004, 25, 1157-1174.

5. Kirschner, K. N.; Yongye, A. B.; Tschampel, S. M.; González-Outeiriño, J.; Daniels, C. R. Foley, B. L.; Woods, R. J. J. Comput. Chem. 2008, 29, 622-655.

6. Gomes, T. C. F.; Skaf, M. S. J. Comput. Chem. 2012, 33, 1338-1346.

7. Liu, Z.; Huang, S.; Wang, W. J. Phys. Chem. B 2004, 108, 12978-12989.

8. Case, D. A.; Babin, V. Berryman, J. T.; Betz, R. M.; Cai, Q.; Cerutti, D. S.; Cheatham III, T. E.; Darden, T. A.; Duke, R. E.; Gohlke, H. AMBER 14.; University of California, 2014. 9. Humphrey, W.; Dalke, A.; Schulten, K. J. Mol. Graph. 1996, 14, 33-38.

10. Ryckaert, J.-P.; Ciccotti, G.; Berendsen, H. J. C. J. Comput. Phys. 1977, 23, 327-341. 